becoming in any way adherent to the wound. The slight irritability and lowered tension of the eye made it seem certain that some foreign body had been carried into the eye, although no sign of it was discoverable after repeated examination, and it was only months afterwards when the cyst appeared pushing forward the eyelash that this judgment was justified. The lash was quite unattached to the cyst and the same was true of the second case, nor did it show any signs of growth although it had, so to speak, been incubated for several months. The method of exposure gave excellent results, it allowed one to get far back in the anterior chamber, especially in the instance of the second cyst in Case I and the slight distortion of the globe and gaping of the wound which could be produced by pulling on the conjunctiva using it as a handle caused the cysts to protrude prominently from the wound so that they were easily removed. The second cyst in Case I was placed so far back that the ciliary processes were clearly seen during operation and the cyst itself was flattened by contact with the edge of the lens. During the removal of this, its walls were lacerated and its contents escaped in part into the anterior chamber. Having regard to the nature of the contents, one would not expect any particular trouble from it nor has any arisen for so long a period of six years. Whether implantation cysts of this nature ever occur apart from the inclusion of an eyelash, I do not know but if so, they must be exceedingly rare.

There is one other point of possible interest, that in each case a small woolly-looking fragment was noticed on the front of the iris which afterwards seemed to disappear, as if in some way it were a precursor of the development of the cyst.

\title{
THE NON-MAGNETISABLE METALLIC FOREIGN BODIES OF THE CORNEA, WITH THE REPORT OF A CASE
}

BY

\section{B. W. RYCROFT}

BRADFORD

Metallic foreign bodies of the cornea may be arbitrarily divided into two classes based on their magnetic properties and it is with the non-magnetic and more uncommon type that I wish to deal, for the treatment of cases in this class may be relatively simple or extremely difficult.

Representative metals of this class are brass, copper, lead, solder and gold; all of these are found as foreign bodies on the cornea. 
and, in addition to their chemical composition, their propelling force and the form in which they reach the eye have an influence on the progress and prognosis of their respective cases.

Brass often occurs as a "turning" which is shaved off the rough metal whilst it is being spun on the lathe, and consequently, it has a spiral shape and is extremely sharp. The propulsive power, however, is tangential and not very great so that it is usual to find part of the foreign body free, which renders the removal of it from the cornea a simple matter.

Copper may be said to occur in two forms, namely as from a percussion cap and as metallic particles rubbed off an overhead electric wire by the passage of a trolley pole over a junction. In the former instance, the fragment enters the eye with great force and the features of a penetrating injury dominate the case, but, in the latter instance, it is the cornea which is chiefly involved. Wurdemann ${ }^{1}$ mentions the intense photophobia which is caused by these pieces of copper oxide, and Maitland Ramsay ${ }^{2}$ quotes Leber as having drawn attention to the marked reaction which follows the presence of copper, even when free of organisms. Rust $^{3}$ has collected twenty-six cases of such corneal injuries by copper and states that twenty-five arose from overhead wires, and one from a travelling crane.

Lead may reach the eye as lead shot or as a splash of molten metal and it is the latter form which chiefly affects the cornea.

In such cases, the large size of the foreign body and the weight of the metal reduce the penetrative force so that it is unusual to find primary penetration of the globe, although secondary perforation by corneal necrosis occurs. Ball ${ }^{4}$ has reported a case in which a lead cast of the cornea and inferior conjunctival fornix was removed from a patient four days after it had been received, and Wurdemann ${ }^{5}$ has described the case of a marker on a military range who had had removed from his cornea particles of lead which had ricochetted from the target after the bullet had hit it. In neither case was the cornea directly perforated.

Solder falls into a different category since it possesses a property of adherence not present, to any great degree, in the other metals, and it is this same physical property which may occasion peculiar difficulties in treatment.

It arrives at the eye in the shape of a single globule, when it pursues a course similar to that of lead, or as minute particles which are sprayed on to the cornea and which not only embed themselves, but make a firm union with the tissue and one which is very difficult to sever. Common solder is a mixture of lead and tin in varying proportions according to the adhesiveness required; it has a low melting point and "balls" of it readily burst. The better type of solder is the silver solder, which is more stable and 
does not tend to spray under high temperatures; it is met with under experimental conditions.

As a foreign body, the occurrence of gold is exceedingly rare but Wurdemann ${ }^{6}$ has met with such a case in a lady who, two weeks after having had her teeth filled, came to him for the removal of a fine piece of the metal impacted in the cornea.

The treatment of these various foreign bodies finally depends on the condition in which they exist in the cornea, namely single or multiple. It may be :

1. Removal by needle or spud when the foreign body is of suitable size.

2. Removal by anticipation of secondary ulceration, when the particles are in a minute state of sub-division. This is particularly applicable to multiple foreign bodies but does not always occur.

3. Removal by burning them out with the galvano-cautery as mentioned by Wood $^{7}$; the final result on the vision is not always satisfactory with this method.

4. Curettage of the corneal epithelium was introduced primarily for the treatment of lead incrustations and may be applied to the multiple foreign bodies, provided they are not too deeply situated in the cornea.

5. Removal may be impossible and, if chemically indifferent, such as lead, they may be tolerated and retained in the cornea. $\left(\mathrm{Fuchs}^{8}\right)$.

6. Suction has been employed by Israel $^{9}$ using a small water suction cylinder, and he states that "practically all characters and kinds of foreign bodies have been removed by this method." The author has recently conducted similar experiments using a reversed blow-pipe vacuum but up to now the results have not been quite so satisfactory.

7. Corneal section may have to be employed as a last resort, and at the Mayo Clinic, Benedict" ${ }^{10}$ dissected off a " quadrilateral section of the cornea, taking all but a narrow zone above and below, down to Descemet's membrane." This occurred in the case of an engineer who received multiple corneal foreign bodies as the result of the explosion of a gasoline still. The final visual acuity was $6 / 30$ and the "cornea was now slightly hazy in the central portion." An interesting feature of this case was that after seven months of intense irritation, the particles had not nearly been exfoliated.

The following case will illustrate a few points in connection with multiple foreign bodies of the cornea due to solder.

E. S., an experimental engineer, was conducting an experiment on a copper ball, which was thought to be silver-soldered and therefore capable of withstanding a steam pressure of about $500 \mathrm{lbs}$. 
per square inch. At $10 \mathrm{lbs}$. pressure, the ball burst and the solder was sprayed on to the patient's face at a distance of approximately nine inches.

Subsequent analysis showed the solder to consist of $65 \%$ tin and $35 \%$ lead, over which a layer of copper had been deposited electrically.

At a pressure of $10 \mathrm{lbs}$., the solder would have no great penetrative power, but would be resolved into minute globules, and the patient states that, in the early stages, the skin on his face was profusely bespattered; this feature was not present when he was examined later.

He continued to work for a fortnight after the accident until increasing photophobia and lacrimation compelled him to report to the Royal Eye and Ear Hospital.

An examination showed a condition of intense bilateral blepharospasm due to photophobia. •

The skin of the eyelids and face was normal and showed no evidence of scars or burns; there were no embedded particles.

Previous general, family and ophthalmic history were negative.

The naso-lacrimal apparatus was normal.

Under cocaine anaesthesia, it was possible to evert the lids. There were no embedded particles in the palpebral or bulbar conjunctiva, but a few were found, freely movable, in the inferior fornix. There was marked superficial conjunctival hyperaemia.

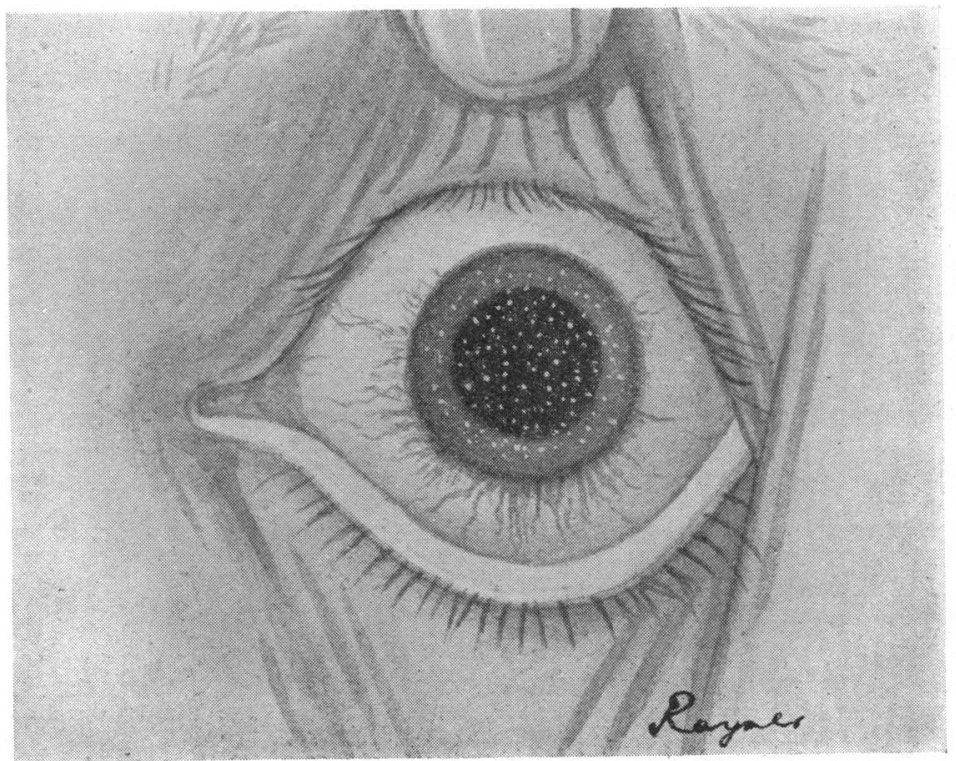


The corneae of both eyes were stippled by a multitude of fine glistening metallic particles, evenly distributed and more marked in the left eye. The minuteness of these fragments is difficult to depict in a drawing, but the accompanying plate, painted under cocaine anaesthesia, gives a fair idea of the condition.

A slit-lamp examination revealed that the foreign bodies were situated in the corneal epithelium and in the superficial layers of the substantia propria. There was no penetration of Descemet's membrane.

The anterior chamber, iris, capsule, lens, and fundus : were normal in both eyes. The digital tension was not raised. The vision was O. D. 6/12, O. S. 6/12.

There was no stain of the corneae with fluorescein or mercurochrome.

Treatment.-The various methods of treatment were considered and it was decided to allow secondary ulceration to occur.

Boracic lavage, atropine mydriasis, and London smoke glasses were prescribed.

At the end of fourteen weeks of this treatment a further investigation showed that, although a few particles had been extruded, there was no great change in the condition.

Epiphora, photophobia and pain remained extreme and a change in the treatment was indicated on this account and for economic reasons.

Accordingly, then, the patient was admitted to hospital for exfoliation of the corneal epithelium.

After a speculum had been inserted into the left eye, the cornea was frequently douched with a $4 \%$ solution of cocaine and allowed to dry.

When the epithelium was uniformly opaque, an attempt was made to remove it by means of cotton wool twisted on a probe.

This had no effect, so that a fine discission needle was employed and, by it, the whole of the epithelium was scraped off until the cornea stained uniformly with. fluorescein. Atropine and flavine in paroleine were then instilled.

It was noticed that although a considerable amount of force was used, few of the foreign bodies were dislodged although the surrounding epithelium was removed, indicating the marked cohesion between the cornea and the metal.

One week later, the condition had improved; the irritation was less and the patient was able to resume his employment. Six weeks later, the foreign bodies had become distinctly fewer and the patient was at work.

The present visual acuity is $6 / 9$ in each eye, but as there are still many particles left on both corneae, this may not be the final result. 
It is a great pleasure for me to thank my chief, Mr. J. Duff McCulloch, for permission to publish this case and gratefully to acknowledge my indebtedness to Messrs. Rayner for providing the drawing.

\section{REFERENCES}

1. Wurdemann.-Injuries of the eye, p. 482, 1912.

Ramsay.-Injuries of the eye, p. 83.

Rust. -Arch. of Ophthal., Vol. XXXVII, 2. 1908.

Ball.-Brit. Jl. of Ophtha!., Vol. XI, 2, p. 73.

Wurdemann.-Injuries of the eye, p. 463, 1912.

Injuries of the eye, p. 452, 1912.

Wood.-System of ophthalmic operations, p. 784.

Fuchs - Textbook of Ophthalmology (Duane), p. 579.

. Israel.-Amer. Jl. of Ophthal., Vol. IX, p. 271, 1926.

10. Benedict. - Proceedings of staff meeting, Mayo clinic, Vol. III, p. : 69, 1928.

\section{MEDIAEVAL OPHTHALMOLOGY IN MESOPOTAMIA}

BY

A. F. Maccallan, C.B.E.

LONDON

"In the name of God, the Compassionate, the Merciful!

" The book of Hunain ibn Is-Haq on the structure of the eye, its diseases and their treatment written in accordance with the opinions of Hippocrates and Galen."

This is the preface to the earliest existing systematic text-book of ophthalmology, which has been translated by Meyerhof of Cairo, and has been published together with the Arabic text by the Government Press, Cairo, 1928.

The history of the discovery of the manuscript is of considerable interest.* When Hirschberg began his investigations of Arabic ophthalmology, with the help of the orientalists Lippert, Mittwoch and Mann, he found Hunain's name frequently mentioned in the old Arabic and Persian text-books on eye diseases as an author of great repute. With admirable philological insight Hirschberg discovered the "Ten Treatises " of Hunain in two Latin translations, one printed at Lyons in 1515, the author being given as Constantinus Africanus, and the other printed at Venice between 1541 and 1625, authorship being attributed to Demetrius, a Sicilian Greek. So both Constantine and Demetrius separately

* MacCallan, "The Birth of Ophthalmology, etc.," Brit. Jl. of Ophthal., Vol. XI, p. $66,1927$. 